\title{
PEMBANGUNAN EKONOMI WILAYAH KABUPATEN CIAMIS BERBASIS KOMODITAS PETERNAKAN
}

\section{ECONOMIC DEVELOPMENT OF CIAMIS DISTRICT BASED ON LIVESTOCK COMMODITIES}

\author{
Agus Yuniawan Isyanto*, Sudrajat, Dedi Herdiansah Sujaya \\ Fakultas Pertanian, Universitas Galuh \\ *Email: gus_yun69@yahoo.co.id \\ (Diterima 16-02-2018; Disetujui 25-04-2018)
}

\begin{abstract}
ABSTRAK
Penelitian dilaksanakan dengan tujuan untuk menganalisis pembangunan ekonomi wilayah Kabupaten Ciamis berbasis sektor peternakan. Data yang digunakan adalah data sekunder berupa data populasi 7 komoditas ternak dari 26 kecamatan di Kabupaten Ciamis. Data dianalisis secara deskriptif kuantitatif dengan menggunakan analisis Location Quotient (LQ). Hasil penelitian menunjukkan bahwa beberapa kecamatan di Kabupaten Ciamis merupakan daerah basis untuk komoditas ternak sapi potong, domba, kambing, ayam buras, ayam ras petelur, ayam ras pedaging dan itik.
\end{abstract}

Kata kunci: Pembangunan ekonomi, LQ, Komoditas, Peternakan

\section{ABSTRACT}

The study was conducted with the aim to analyze the economic development of Ciamis District based on livestock sector. The data used are secondary data in the form of population of 7 livestock commodities from 26 subdistricts in Ciamis Distict. The data were analyzed quantitative descriptive by using Location Quotient (LQ) analysis. The results showed that some subdistricts in Ciamis District were the base areas for beef cattle, sheep, goats, domestic poultry, laying chicken, broiler and duck.

Keywords: Economic development, LQ, Commodities, Livestock

\section{PENDAHULUAN}

Strategi pembangunan ekonomi di Indonesia dapat dikelompokkan dalam dua pendekatan, yaitu pertumbuhan yang seimbang dan pertumbuhan yang tidak seimbang. Fakta empiris menunjukkan bahwa sektor basis mampu berkembang dan berkontribusi besar terhadap pembangunan ekonomi, sedangkan sektor non basis lebih rendah kontribusinya
(Suseno dan Anas, 2017).

Setiap wilayah memiliki potensi sumberdaya yang berbeda, sehingga diperlukan suatu kajian mengenai potensi sumberdaya yang menjadi unggulan dari setiap wilayah tersebut sebagai dasar dalam pembuatan kebijakan pengembangan wilayah yang tepat (Rustandi, 2016). Salah satu kebijakan pembangunan ekonomi wilayah adalah 


\section{PEMBANGUNAN EKONOMI WILAYAH KABUPATEN CIAMIS \\ BERBASIS KOMODITAS PETERNAKAN \\ Agus Yuniawan Isyanto, Sudrajat, Dedi Herdiansah Sujaya}

pengembangan kawasan andalan berbasis potensi wilayah tersebut (Munandar, et al, 2017; Mursidah, dkk., 2013).

Setiap wilayah harus mengambil kebijakan yang tepat dalam mengoptimalkan potensi yang dimilikinya untuk meningkatkan pertumbuhan ekonomi di wilayah tersebut (Adhitama, 2012). Untuk mempercepat pembangunan ekonomi lokal dalam rangka meningkatkan kesejahteraan sosial dan daya saing daerah, pembangunan ekonomi dapat dikembangkan melalui pengembangan potensi sektor ekonomi yang menjadi unggulan daerah (Puspaningtyas, et al, 2013).

Pembangunan ekonomi suatu wilayah ditujukan untuk mewujudkan kesejahteraan masyarakat di wilayah tersebut dengan menitikberatkan pada sektor ekspor yang dapat menghasilkan devisa sebagai investasi input internal pada sektor-sektor lain yang tidak memiliki kemampuan untuk melakukan ekspor (Juswadi, 2017). Kesejahteraan masyarakat diturunkan dari pembangunan wilayah melalui pembangunan yang berkelanjutan. Salah satu instrumen pengukuran pembangunan wilayah berkelanjutan adalah daya saing wilayah. Semakin tinggi daya saing suatu wilayah, maka semakin tinggi pula kesejahteraan masyarakat di wilayah tersebut (Khusaini, 2015).

Hoover (1984) dalam Fafurida, et al (2016) menyatakan bahwa pertumbuhan sektor basis akan mempengaruhi pertumbuhan ekonomi regional yang menjadi sumber pendapatan daerah dan meningkatkan konsumsi serta investasi. Peningkatan pendapatan daerah tersebut akan mendorong peningkatan permintaan terhadap produk dari sektor non-basis yang akan meningkatkan investasi pada sektor non-basis.

Berdasarkan uraian di atas, maka penelitian ini dilaksanakan dengan tujuan untuk menganalisis pembangunan ekonomi wilayah Kabupaten Ciamis berbasis komoditas peternakan dengan cara mengidentifikasi potensi ternak unggulan pada masing-masing kecamatan di wilayah Kabupaten Ciamis.

\section{TINJAUAN PUSTAKA}

Pembangunan wilayah merupakan suatu upaya yang terpadu yang bertujuan untuk mendorong pertumbuhan taraf sosial dan ekonomi dari masyarakat di wilayah tersebut, menurunkan kesenjangan antar wilayah dan menjaga kelestarian lingkungan hidup (Riyadi, 
2002 dalam Yuda dan Navitas, 2014).

Fokus pembangunan wilayah adalah pembangunan antar wilayah, masalah agrolomerasi, dan menurunnya daya tarik perdesaan (Rustiadi, dkk., 2011).

Kebijaksanaan pembangunan ekonomi suatu wilayah berdasarkan prinsip keunggulan kompetitif dapat dilakukan melalui pengembangan komoditas unggulan. Kebijakan ini dilakukan dengan mengembangkan komoditas utama yang mempunyai dayasaing tinggi yang didukung oleh keunggulan kompetitif wilayah tersebut (Jauhariyah dan Inayah, 2016).

Pembangunan ekonomi suatu daerah terkait dengan pertumbuhan ekonomi (Mangilelang, dkk., 2015). Pertumbuhan ekonomi yang berkualitas adalah pertumbuhan ekonomi yang berorientasi pada penciptaan kesempatan kerja dan berpihak pada penurunan angka kemiskinan (Badrudin, 2012).

Pembangunan ekonomi dari suatu daerah adalah suatu proses yang dilaksanakan oleh pemerintah daerah dan masyarakat dalam mengelola sumberdaya yang ada pada daerah tersebut. Suatu daerah akan memiliki sektor unggulan apabila daerah tersebut memiliki kemampuang bersaing yang lebih tinggi dibandingkan dengan daerah lain pada sektor yang sama (Kurniawan, 2016).

Potensi ekonomi suatu daerah menunjukkan sejauhmana potensi sumberdaya alam dan sumberdaya manusia yang dimilikinya dapat memberikan kontribusi produktif terhadap pembangunan perekonomian di daerah tersebut (Syamsiah, dkk., 2017).

Pembangunan sektor pertanian pada suatu wilayah dipengaruhi oleh keunggulan kompetitif, spesialisasi serta potensi pertanian yang ada pada wilayah tersebut. Potensi pertanian tersebut tidak akan berpengaruh bagi pembangunan sektor pertanian di wilayah tersebut apabila tidak dimanfaatkan dan dikembangkan secara optimal (Wicaksono, 2011). Usaha peternakan merupakan usaha yang potensial untuk dikembangkan di wilayah pedesaan maupun pinggiran kota pada negeranegara berkembang seperti Indonesia (Siagian, 2011).

LQ adalah suatu metode yang membandingkan sumbangan nilai tambah dari suatu sektor pada suatu wilayah yang lebih kecil terhadap nilai tambah sektor yang bersangkutan pada wilayah yang lebih luas. Metode ini umumnya dipakai untuk mengidentifikasi sektor unggulan (basis) yang memiliki potensi untuk dikembangkan secara optimal (Syamsiah, 


\section{PEMBANGUNAN EKONOMI WILAYAH KABUPATEN CIAMIS \\ BERBASIS KOMODITAS PETERNAKAN \\ Agus Yuniawan Isyanto, Sudrajat, Dedi Herdiansah Sujaya}

dkk., 2017).

Metode LQ merupakan perbandingan antara pangsa relatif pendapatan (tenaga kerja) sektor i pada tingkat wilayah terhadap pendapatan (tenaga kerja) total wilayah dengan pangsa relatif pendapatan (tenaga kerja) sektor i pada tingkat nasional terhadap pendapatan (tenaga kerja) nasional (Sirait, 2013).

\section{METODE PENELITIAN}

Penelitian dilaksanakan dengan menggunakan metode deskriptif kuantitatif untuk mengidentifikasi potensi ternak unggulan di wilayah Kabupaten Ciamis. Data yang digunakan berupa data sekunder yang dipublikasi oleh Badan Pusat Statistik (BPS) Kabupaten Ciamis. Tujuh komoditas ternak yang dianalisis meliputi ternak sapi potong, domba, kambing, ayam bukan ras (buras), ayam ras petelur, ayam ras pedaging dan itik dari 26 kecamatan yang ada di wilayah Kabupaten Ciamis.

Analisis pembangunan ekonomi wilayah Kabupaten Ciamis berbasis komoditas peternakan didekati dengan menggunakan analisis Location Quotient (LQ) dengan menggunakan data populasi ternak sebagai dasar analisis. Data populasi ternak tersebut diperoleh dari publikasi BPS Kabupaten Ciamis (2016). Sebelum dilakukan perhitungan dengan menggunakan analisis LQ, maka masingmasing populasi ternak tersebut dikonversi dengan menggunakan satuan ternak (ST).

Model LQ yang digunakan dalam penelitian ini menggunakan model persamaan yang digunakan oleh Daud (2009) sebagai berikut:

$$
L Q=\frac{X_{i j} / \sum_{i=n}^{7} X_{i j}}{\sum_{i=1}^{26} X_{i j} / \sum_{j=1}^{26} \sum_{i=1}^{5} X_{i j}}
$$

Keterangan:

$$
\begin{aligned}
& X_{i j} \quad=\text { Populasi ternak jenis ke-i } \\
& \text { dalam satuan ternak } \\
& \text { ruminansia (ST) di } \\
& \text { kecamatan ke-j. } \\
& \sum_{\substack{\mathrm{n}=7 \\
\mathrm{i}=1} \mathrm{x}_{\mathrm{i}}^{\prime}=}=7 \text { Total satuan ternak (dari } \\
& \text { kecamatan ke-j (ST). }
\end{aligned}
$$

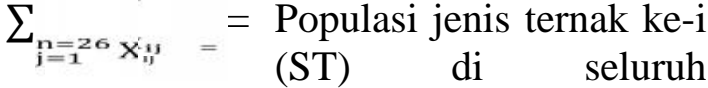

$$
\begin{aligned}
& \text { kecamatan atau di } \\
& \text { wilayah kabupaten yang }
\end{aligned}
$$

Apabila nilai LQ untuk jenis ternak tertentu di kecamatan ke-j lebih besar atau sama dengan satu (LQ $\geq 1)$, maka kecamatan tersebut merupakan daerah basis bagi komoditas ternak tersebut. Sebaliknya, apabila nilai LQ lebih kecil dari satu (LQ < 1), maka kecamatan 
tersebut bukan daerah basis bagi komoditas ternak tertentu.

\section{HASIL DAN PEMBAHASAN}

Pembangunan ekonomi wilayah

Kabupaten Ciamis berbasis komoditas peternakan didekati dengan menggunakan analisis LQ. Hasil analisis LQ untuk komoditas peternakan di Kabupaten Ciamis dapat dilihat pada Tabel 1.

Tabel 1. Perhitungan LQ Komoditas Peternakan di Kabupaten Ciamis

\begin{tabular}{|c|c|c|c|c|c|c|c|c|}
\hline No. & Kecamatan & $\begin{array}{c}\text { Sapi } \\
\text { potong }\end{array}$ & Domba & Kambing & $\begin{array}{l}\text { Ayam } \\
\text { buras }\end{array}$ & $\begin{array}{l}\text { Ayam ras } \\
\text { petelur }\end{array}$ & $\begin{array}{l}\text { Ayam ras } \\
\text { pedaging }\end{array}$ & Itik \\
\hline 1. & Banjarsari & 2.67 & 4.85 & 2.53 & 2.26 & 2.89 & 0.78 & 5.34 \\
\hline 2. & Lakbok & 3.35 & 1.83 & 19.26 & 18.53 & 0.00 & 0.17 & 11.55 \\
\hline 3. & Pamarican & 11.25 & 15.02 & 18.03 & 3.22 & 0.00 & 0.00 & 5.96 \\
\hline 4. & Cidolog & 3.08 & 2.86 & 2.79 & 2.34 & 0.71 & 0.81 & 14.46 \\
\hline 5. & Cimaragas & 0.23 & 0.25 & 0.19 & 1.86 & 0.54 & 1.04 & 0.27 \\
\hline 6. & Cijeungjing & 20.51 & 3.81 & 1.48 & 13.29 & 0.00 & 0.45 & 1.26 \\
\hline 7. & Cisaga & 6.51 & 2.04 & 8.32 & 3.07 & 1.46 & 0.69 & 0.22 \\
\hline 8. & Tambaksari & 1.49 & 0.34 & 0.51 & 0.38 & 0.84 & 1.04 & 0.08 \\
\hline 9. & Rancah & 5.06 & 4.32 & 6.84 & 0.62 & 0.00 & 0.73 & 0.08 \\
\hline 10. & Rajadesa & 0.28 & 0.22 & 0.10 & 0.85 & 0.00 & 1.07 & 0.12 \\
\hline 11. & Sukadana & 1.84 & 1.95 & 2.86 & 4.99 & 0.45 & 0.85 & 0.43 \\
\hline 12. & Ciamis & 2.00 & 1.57 & 1.07 & 1.70 & 0.09 & 0.96 & 1.54 \\
\hline 13. & Cikoneng & 7.62 & 2.64 & 0.24 & 8.36 & 2.18 & 0.73 & 6.99 \\
\hline 14. & Cihaubeuti & 0.67 & 3.12 & 2.65 & 1.41 & 1.63 & 0.89 & 0.71 \\
\hline 15. & Sadananya & 1.04 & 0.37 & 0.48 & 3.09 & 0.30 & 1.00 & 0.05 \\
\hline 16. & Cipaku & 0.25 & 2.12 & 2.96 & 1.60 & 0.87 & 0.92 & 1.99 \\
\hline 17. & Jatinagara & 0.06 & 0.70 & 0.32 & 0.74 & 0.15 & 1.05 & 0.36 \\
\hline 18. & Panawangan & 4.95 & 9.31 & 7.89 & 1.93 & 0.00 & 0.53 & 0.20 \\
\hline 19. & Kawali & 0.02 & 0.55 & 0.08 & 0.38 & 3.80 & 1.04 & 0.00 \\
\hline 20. & Panjalu & 16.13 & 14.69 & 1.60 & 8.16 & 0.74 & 0.01 & 80.65 \\
\hline 21. & Panumbangan & 0.57 & 0.56 & 0.64 & 0.37 & 0.03 & 1.05 & 0.22 \\
\hline 22. & Sindangkasih & 0.22 & 0.16 & 0.31 & 0.32 & 0.02 & 1.07 & 0.12 \\
\hline 23. & Baregbeg & 2.27 & 2.11 & 2.10 & 2.83 & 2.48 & 0.87 & 3.58 \\
\hline 24. & Lumbung & 0.01 & 0.11 & 0.09 & 0.43 & 0.00 & 1.08 & 0.14 \\
\hline 25. & Purwadadi & 0.04 & 1.11 & 1.02 & 0.39 & 0.73 & 1.02 & 0.26 \\
\hline 26. & Sukamantri & 1.16 & 0.79 & 0.41 & 0.94 & 7.84 & 0.98 & 1.11 \\
\hline
\end{tabular}

Sumber: Analisis Data Sekunder, 2018

\section{Komoditas Ternak Sapi Potong}

Hasil perhitungan dengan menggunakan analisis LQ menunjukkan bahwa kecamatan yang merupakan daerah basis untuk komoditas ternak sapi potong adalah kecamatan Cimaragas, Rajadesa, Cihaurbeuti, Cipaku, Jatinagara, Kawali, Panumbangan, 


\section{PEMBANGUNAN EKONOMI WILAYAH KABUPATEN CIAMIS \\ BERBASIS KOMODITAS PETERNAKAN \\ Agus Yuniawan Isyanto, Sudrajat, Dedi Herdiansah Sujaya}

Sindangkasih, Lumbung, Purwadadi. pada Tabel 2.

Hasil analisis selengkapnya dapat dilihat

Tabel 2. Nilai L/Q Untuk Komoditas Ternak Sapi Potong

\begin{tabular}{ccl}
\hline No & Nilai L/Q & \multicolumn{1}{c}{ Kecamatan } \\
\hline 1 & $\geq 1$ & $\begin{array}{l}\text { Banjarsari, Lakbok, Pamarican, Cidolog, Cijeungjing, Cisaga, } \\
\text { Tambaksari. Rancah, Sukadana, Ciamis, Cikoneng, Sadananya, }\end{array}$ \\
& & $\begin{array}{l}\text { Panawangan, Panjalu, Baregbeg, Sukamantri } \\
\text { Cimaragas, Rajadesa, Cihaurbeuti, Cipaku, Jatinagara, Kawali, } \\
\text { Panumbangan, Sindangkasih, Lumbung, Purwadadi }\end{array}$ \\
\hline
\end{tabular}

Tabel 2 menunjukkan bahwa kecamatan yang merupakan daerah basis untuk komoditas ternak sapi potong adalah kecamatan Banjarsari, Lakbok, Pamarican, Cidolog, Cijeungjing, Cisaga, Tambaksari. Rancah, Sukadana, Ciamis, Cikoneng, Sadananya, Panawangan, Panjalu, Baregbeg, Sukamantri. Seluruh kecamatan ini telah dapat memenuhi kebutuhannya sendiri terhadap komoditas ternak sapi potong, dan bahkan dapat mengekspor komoditas tersebut ke kecamatan lain atau bahkan ke luar wilayah Kabupaten Ciamis.

\section{Komoditas Ternak Domba}

Hasil perhitungan dengan menggunakan analisis LQ menunjukkan bahwa kecamatan yang merupakan daerah bukan basis untuk komoditas ternak domba adalah kecamatan Cimaragas, Tambaksari, Rajadesa, Sadananya, Jatinagara, Kawali, Panumbangan, Sindangkasih, Lumbung, Sukamantri. Hasil analisis selengkapnya dapat dilihat pada Tabel 3 .

Tabel 3. Nilai L/Q Untuk Komoditas Ternak Domba

\begin{tabular}{cclll}
\hline No & Nilai L/Q & \multicolumn{3}{c}{ Kecamatan } \\
\hline 1 & $\geq 1$ & $\begin{array}{l}\text { Banjarsari, Lakbok, Pamarican, Cidolog, Cijeungjing, Cisaga, } \\
\text { Rancah, Sukadana, Ciamis, Cikoneng, Cihaubeuti, Cipaku, }\end{array}$ \\
& & $\begin{array}{l}\text { Panawangan, Panjalu, Baregbeg, Purwadadi } \\
\text { Cimaragas, Tambaksari, Rajadesa, Sadananya, Jatinagara, Kawali, } \\
\text { Panumbangan, Sindangkasih, Lumbung, Sukamantri }\end{array}$ \\
\hline
\end{tabular}

Tabel 3 menunjukkan bahwa kecamatan yang merupakan daerah basis untuk komoditas ternak domba adalah kecamatan Banjarsari, Lakbok, Pamarican, Cidolog, Cijeungjing, Cisaga,
Rancah, Sukadana, Ciamis, Cikoneng, Cihaubeuti, Cipaku, Panawangan, Panjalu, Baregbeg, Purwadadi. Seluruh kecamatan ini telah dapat memenuhi kebutuhannya sendiri terhadap komoditas 
ternak domba, dan bahkan dapat mengekspor komoditas tersebut ke kecamatan lain atau bahkan ke luar wilayah Kabupaten Ciamis.

\section{Komoditas Ternak Kambing}

Hasil perhitungan dengan menggunakan analisis LQ menunjukkan bahwa kecamatan yang merupakan daerah bukan basis untuk komoditas ternak kambing adalah kecamatan Cimaragas, Tambaksari, Rajadesa, Cikoneng, Sadananya, Jatinagara, Kawali, Panumbangan, Sindangkasih, Lumbung, Sukamantri. Hasil analisis selengkapnya dapat dilihat pada Tabel 4.

\section{Tabel 4. Nilai L/Q Untuk Komoditas Ternak Kambing}

\begin{tabular}{|c|c|c|}
\hline No & Nilai L/Q & Kecamatan \\
\hline 1 & $\geq 1$ & $\begin{array}{l}\text { Banjarsari, Lakbok, Pamarican, Cidolog, Cijeungjing, Cisaga, } \\
\text { Rancah, Sukadana, Ciamis, Cihaubeuti, Cipaku, Panawangan, } \\
\text { Panjalu, Baregbeg, Lumbung, Purwadadi }\end{array}$ \\
\hline 2 & $<1$ & $\begin{array}{l}\text { Cimaragas, Tambaksari, Rajadesa, Cikoneng, Sadananya, Jatinagara, } \\
\text { Kawali, Panumbangan, Sindangkasih, Lumbung, Sukamantri }\end{array}$ \\
\hline
\end{tabular}

Tabel 4 menunjukkan bahwa kecamatan yang merupakan daerah basis untuk komoditas ternak kambing adalah kecamatan Banjarsari, Lakbok, Pamarican, Cidolog, Cijeungjing, Cisaga, Rancah, Sukadana, Ciamis, Cihaubeuti, Cipaku, Panawangan, Panjalu, Baregbeg, Lumbung, Purwadadi. Seluruh kecamatan ini telah dapat memenuhi kebutuhannya sendiri terhadap komoditas ternak kambing, dan bahkan dapat mengekspor komoditas tersebut ke kecamatan lain atau bahkan ke luar wilayah Kabupaten Ciamis.

\section{Komoditas Ternak Ayam Buras}

Hasil perhitungan dengan menggunakan analisis LQ menunjukkan bahwa kecamatan yang merupakan daerah bukan basis untuk komoditas ternak ayam buras adalah kecamatan Tambaksari, Rancah, Rajadesa, Jatinagara, Kawali, Panumbangan, Sindangkasih, Lumbung, Purwadadi, Sukamantri. Hasil analisis selengkapnya dapat dilihat pada Tabel 5.

\section{Tabel 5. Nilai L/Q Untuk Komoditas Ternak Ayam Buras}

\begin{tabular}{|c|c|c|}
\hline No & Nilai L/Q & Kecamatan \\
\hline 1 & $\geq 1$ & $\begin{array}{l}\text { Banjarsari, Lakbok, Pamarican, Cidolog, Cimaragas, Cijeungjing, } \\
\text { Cisaga, Sukadana, Ciamis, Cikoneng, Cihaubeuti, Sadananya, } \\
\text { Cipaku, Panawangan, Panjalu, Baregbeg }\end{array}$ \\
\hline 2 & $<1$ & $\begin{array}{l}\text { Tambaksari, Rancah, Rajadesa, Jatinagara, Kawali, Panumbangan, } \\
\text { Sindangkasih, Lumbung, Purwadadi, Sukamantri }\end{array}$ \\
\hline
\end{tabular}




\section{PEMBANGUNAN EKONOMI WILAYAH KABUPATEN CIAMIS \\ BERBASIS KOMODITAS PETERNAKAN \\ Agus Yuniawan Isyanto, Sudrajat, Dedi Herdiansah Sujaya}

Tabel 5 menunjukkan bahwa kecamatan yang merupakan daerah basis untuk komoditas ternak ayam buras adalah kecamatan Banjarsari, Lakbok, Pamarican, Cidolog, Cimaragas, Cijeungjing, Cisaga, Sukadana, Ciamis, Cikoneng, Cihaubeuti, Sadananya, Cipaku, Panawangan, Panjalu, Baregbeg. Seluruh kecamatan ini telah dapat memenuhi kebutuhannya sendiri terhadap komoditas ternak ayam buras, dan bahkan dapat mengekspor komoditas tersebut ke kecamatan lain atau bahkan ke luar wilayah Kabupaten Ciamis.
Komoditas Ternak Ayam Ras Petelur Hasil perhitungan dengan menggunakan analisis LQ menunjukkan bahwa kecamatan yang merupakan daerah bukan basis untuk komoditas ternak ayam ras petelur adalah kecamatan Lakbok, Pamarican, Cidolog, Cimaragas, Cijeungjing, Tambaksari, Rancah, Rajadesa, Sukadana, Ciamis, Sadananya, Cipaku, Jatinagara, Panawangan, Panjalu, Panumbangan, Sindangkasih, Lumbung, Purwadadi. Hasil analisis selengkapnya dapat dilihat pada Tabel 6 .

\section{Tabel 6. Nilai L/Q Untuk Komoditas Ternak Ayam Ras Petelur}

\begin{tabular}{|c|c|c|}
\hline No & Nilai L/Q & Kecamatan \\
\hline 1 & $\geq 1$ & $\begin{array}{l}\text { Banjarsari, Cisaga, Cikoneng, Cihaubeuti, Kawali, Baregbeg, } \\
\text { Sukamantri }\end{array}$ \\
\hline 2 & $<1$ & $\begin{array}{l}\text { Lakbok, Pamarican, Cidolog, Cimaragas, Cijeungjing, Tambaksari, } \\
\text { Rancah, Rajadesa, Sukadana, Ciamis, Sadananya, Cipaku, Jatinagara, } \\
\text { Panawangan, Panjalu, Panumbangan, Sindangkasih, Lumbung, } \\
\text { Purwadadi }\end{array}$ \\
\hline
\end{tabular}

Tabel 6 menunjukkan bahwa kecamatan yang merupakan daerah basis untuk komoditas ternak ayam ras petelur adalah Banjarsari, Cisaga, Cikoneng, Cihaubeuti, Kawali, Baregbeg, Sukamantri. Seluruh kecamatan ini telah dapat memenuhi kebutuhannya sendiri terhadap komoditas ternak ayam ras petelur, dan bahkan dapat mengekspor komoditas tersebut ke kecamatan lain atau bahkan ke luar wilayah Kabupaten Ciamis.

\section{Komoditas Ternak Ayam Ras Pedaging}

Hasil perhitungan dengan menggunakan analisis LQ menunjukkan bahwa kecamatan yang merupakan daerah bukan basis untuk komoditas ternak ayam ras pedaging adalah kecamatan Banjarsari, Lakbok, Pamarican, Cidolog, Cijeungjing, Cisaga, Rancah, Sukadana, Ciamis, Cikoneng, Cihaurbeuti, Cipaku, Panawangan, Panjalu, Baregbeg, Sukamantri. Hasil 
analisis selengkapnya dapat dilihat pada

Tabel 7.

\section{Tabel 7. Nilai L/Q Untuk Komoditas Ayam Ras Pedaging}

\begin{tabular}{ccllc}
\hline No & Nilai L/Q & \multicolumn{4}{c}{ Kecamatan } \\
\hline 1 & $\geq 1$ & $\begin{array}{l}\text { Cimaragas, Tambaksari, Rajadesa, Sadananya, Jatinagara, Kawali, } \\
\text { Panumbangan, Sindangkasih, Lumbung, Purwadadi }\end{array}$ \\
2 & $<1$ & $\begin{array}{l}\text { Banjarsari, Lakbok, Pamarican, Cidolog, Cijeungjing, Cisaga, } \\
\text { Rancah, Sukadana, Ciamis, Cikoneng, Cihaurbeuti, Cipaku, } \\
\end{array}$ & Panawangan, Panjalu, Baregbeg, Sukamantri
\end{tabular}

Tabel 7 menunjukkan bahwa kecamatan yang merupakan daerah basis untuk komoditas ternak ayam ras pedaging adalah Cimaragas, Tambaksari, Rajadesa, Sadananya, Jatinagara, Kawali, Panumbangan, Sindangkasih, Lumbung, Purwadadi. Seluruh kecamatan ini telah dapat memenuhi kebutuhannya sendiri terhadap komoditas ternak ayam ras pedaging, dan bahkan dapat mengekspor komoditas tersebut ke kecamatan lain atau bahkan ke luar wilayah Kabupaten Ciamis.
Komoditas Ternak Itik

Hasil perhitungan dengan menggunakan analisis LQ menunjukkan bahwa kecamatan yang merupakan daerah bukan basis untuk komoditas ternak itik adalah kecamatan Cimaragas, Cisaga, Tambaksari, Rancah, Rajadesa, Sukadana, Cihaubeuti, Sadananya, Jatinagara, Panawangan, Kawali, Panumbangan, Sindangkasih, Lumbung, Purwadadi. Hasil analisis selengkapnya dapat dilihat pada Tabel 8 .

Tabel 8. Nilai L/Q Untuk Komoditas Ternak Itik

\begin{tabular}{cclcc}
\hline No & Nilai L/Q & \multicolumn{3}{c}{ Kecamatan } \\
\hline 1 & $\geq 1$ & $\begin{array}{l}\text { Banjarsari, Lakbok, Pamarican, Cidolog, Cijeungjing, Ciamis, } \\
\text { Cikoneng, Cipaku, Panjalu, Baregbeg, Purwadadi }\end{array}$ \\
2 & $<1$ & $\begin{array}{l}\text { Cimaragas, Cisaga, Tambaksari, Rancah, Rajadesa, Sukadana, } \\
\text { Cihaubeuti, Sadananya, Jatinagara, Panawangan, }\end{array}$ & Kawali, \\
& & Panumbangan, Sindangkasih, Lumbung, Purwadadi & \\
\hline
\end{tabular}

Tabel 8 menunjukkan bahwa kecamatan yang merupakan daerah basis untuk komoditas ternak itik adalah Banjarsari, Lakbok, Pamarican, Cidolog, Cijeungjing, Ciamis, Cikoneng, Cipaku, Panjalu, Baregbeg, Purwadadi. Seluruh kecamatan ini telah dapat memenuhi kebutuhannya sendiri terhadap komoditas ternak itik, dan bahkan dapat mengekspor komoditas tersebut ke kecamatan lain atau bahkan ke luar wilayah Kabupaten Ciamis. 


\section{PEMBANGUNAN EKONOMI WILAYAH KABUPATEN CIAMIS \\ BERBASIS KOMODITAS PETERNAKAN \\ Agus Yuniawan Isyanto, Sudrajat, Dedi Herdiansah Sujaya}

PENUTUP

Daerah basis untuk komoditas ternak sapi potong adalah kecamatan Banjarsari, Lakbok, Pamarican, Cidolog, Cijeungjing, Cisaga, Tambaksari. Rancah, Sukadana, Ciamis, Cikoneng, Sadananya, Panawangan, Panjalu, Baregbeg, dan Sukamantri.

Daerah basis untuk komoditas ternak domba adalah kecamatan Banjarsari, Lakbok, Pamarican, Cidolog, Cijeungjing, Cisaga, Rancah, Sukadana, Ciamis, Cikoneng, Cihaubeuti, Cipaku, Panawangan, Panjalu, Baregbeg, dan Purwadadi.

Daerah basis untuk komoditas ternak kambing adalah kecamatan Banjarsari, Lakbok, Pamarican, Cidolog, Cijeungjing, Cisaga, Rancah, Sukadana, Ciamis, Cihaubeuti, Cipaku, Panawangan, Panjalu, Baregbeg, Lumbung, dan Purwadadi.

Daerah basis untuk komoditas ternak ayam buras adalah kecamatan Banjarsari, Lakbok, Pamarican, Cidolog, Cimaragas, Cijeungjing, Cisaga, Sukadana, Ciamis, Cikoneng, Cihaubeuti, Sadananya, Cipaku, Panawangan, Panjalu, dan Baregbeg.

Daerah basis untuk komoditas ternak ayam ras petelur adalah kecamatan Banjarsari, Cisaga, Cikoneng,
Cihaubeuti, Kawali, Baregbeg, dan Sukamantri.

Daerah basis untuk komoditas ternak ayam ras pedaging adalah kecamatan Cimaragas, Tambaksari, Rajadesa, Sadananya, Jatinagara, Kawali, Panumbangan, Sindangkasih, Lumbung, dan Purwadadi.

Daerah basis untuk komoditas ternak itik adalah kecamatan Banjarsari, Lakbok, Pamarican, Cidolog, Cijeungjing, Ciamis, Cikoneng, Cipaku, Panjalu, Baregbeg, dan Purwadadi.

\section{DAFTAR PUSTAKA}

Adhitama, R. 2012. Pengembangan Sektor-sektor Ekonomi di Tiap Kecamatan di Kabupaten Magelang. Economics Development Analysis Journal, 1(2): 1-9.

Alhempi, R.R., Zainah, H. dan Kusumastuti, $\quad$ S.Y. 2014. Keterkaitan Sektor-sektor Ekonomi Potensial di Provinsi Riau. Mimbar, 30(1): 62-71.

Badan Pusat Statistik Kabupaten Ciamis. 2016. Kabupaten Ciamis Dalam Angkat 2016. Ciamis.

Badrudin, R. 2012. Pengembangan Ekonomi Lokal Kabupaten/Kota Provinsi Daerah Istimewa Yogyakarta Menggunakan Tipologi Klasen dan Location Quotient. $J R M B, 7(1): 17-37$.

Daud, A.R. 2009. Analisis Potensi Wilayah Pengembangan Ternak Ruminansia di Kabupaten Purwakarta. Sosiohumaniora, 11(2): 126-139.

Dinc, M. 2002. Regional and Local Economic Analysis Tools. Prepared 
for the Public Finance, Decentralization and Poverty Reduction Program. World Bank Institute. Washington, DC: The World Bank.

Fafurida, F., Setiawan, A.B. dan Irmawati, S. 2016. A Strategy to Increase the Competitiveness of Leading Industries in Central Java Province to Face ASEAN Economics Community 2015. International Journal of Economics and Financial Issues, 6(S6): 60-66.

Hafied, H. 2009. Ekonomi Pembangunan \& Perencanaan. Cetakan I September 2009. Makasar: Kretakupa Print.

Jauhariyah, N.A. dan Inayah, N. 2016. Analisis Sektor Ekonomi Unggulan di Kabupaten Banyuwangi. Malia, 8(1): 85-98.

Juswadi, J. 2017. Pengembangan Sektor Industri Pengolahan Berbasis Produk Pertanian di KabupatenKabupaten Provinsi Jawa Barat. Agri Wiralodra, 9(1): 8-15.

Khusaini, M. 2015. A shift-share analysis on regional competitiveness - a case of Banyuwangi district, East Java, Indonesia. Procedia - Social and Behavioral Sciences 211(2015): 738-744.

Kurniawan, B. 2016. Analisis Sektor Ekonomi Unggulan Kabupaten Kerinci Provinsi Jambi. el-JIZYA Jurnal Ekonomi Islam, 4(1): 1-26.

Mangilaleng, E.J., Rotinsulu, D. dan Rompas, W. 2015. Analisis Sektor Unggulan Kabupaten

Minahasa Selatan. Jurnal Berkala Ilmiah Efisiensi, 15(04): 193-205.

Munandar, T.A., Azhari, Musdholifah, A. dan Arsyad, L. 2017. Modified Agglomerative Clustering With Location Quotient for Identification of Regional Potential Sector. Journal of Theoretical and Applied Information Technology, 95(5):
1191-1199.

Mursidah, Hamzah, A. dan Sofyan. 2013. Analisis Pengembangan Kawasan Andalan di Kabupaten Aceh Besar. Jurnal Ilmu Ekonomi Pascasarjana Universitas Syiah Kuala, 1(1): 4355.

Puspaningtyas, A., Rochmah, S. dan Mindarti, L.E. 2013. Analysis of Local Economic Potential and Competitiveness Economic Sector in Improving Local Economic Development (Study in Batu City). Jurnal Administrasi Publik (JAP), 3(1): 151-156.

Rustandi, Y. 2016. Potensi Komoditas Peternakan dalam Pemenuhan Ketersediaan Pangan Asal Ternak di Kota Tarakan. Agrica Ekstensia, 10(2): 55-60.

Rustiadi, E., Saefulhakim, S. dan Panuju, D.R. 2011. Perencanaan dan Pengembangan Wilayah. Jakarta: Crestpent Press dan Yayasan Obor Indonesia.

Siagian, H. 2011. Kontribusi Usaha Peternakan dalam Pengembangan Wilayah. Jurnal Wira Ekonomi Mikroskil, 1(01): 31-35.

Sirait, M. 2013. Kajian Pengembangan Perikanan Berbasis Komoditas Unggulan. Jurnal Kelautan, 6(2): 150-156.

Suseno, D.A. dan Anas, M.A. 2017. Multiplier Effect Sektor Basis Terhadap Perekonomian Daerah Provinsi Jawa Tengah. Jurnal Riset Ekonomi Pembangunan, 2(2): 113126.

Syamsiyah, N., Sulistyodewi, S. dan Karyani, T. 2017. Wilayah Potensial dalam Pengembangan Agrowisata Buah di Kabupaten Cirebon. Optima, 1(2): 1-9.

Wicaksono, I.A. 2011. Analisis Location Quotient Sektor dan Subsektor Pertanian pada Kecamatan di Kabupaten Purworejo. Mediagro, 


\section{PEMBANGUNAN EKONOMI WILAYAH KABUPATEN CIAMIS BERBASIS KOMODITAS PETERNAKAN}

Agus Yuniawan Isyanto, Sudrajat, Dedi Herdiansah Sujaya

7(2): $11-18$

Yuda, D.K. dan Navitas, P. 2014. Arahan

Pengembangan

Ekonomi

Kabupaten Lamongan Berdasarkan

Sektor Unggulan (Studi Kasus:

Sektor Pertanian). Jurnal Teknik

Pomits, 3(2): C136-C141. 